\title{
INFLUÊNCIA DA COBERTURA VEGETAL DO SOLO NA QUALIDADE DOS FRUTOS DE VIDEIRA 'NIAGARA ROSADA'1
}

\author{
ELAINE BAHIA WUTKE 2 , MAURILO MONTEIRO TERRA ${ }^{3}$, ERASMO JOSÉ PAIOLI PIRES ${ }^{3}$, FABIO COSTA ${ }^{3}$, \\ ISMAEL LUIZ SECCO ${ }^{4}$, IVAN JOSÉ ANTUNES RIBEIRO ${ }^{3}$
}

\begin{abstract}
RESUMO - Devido ao aumento no custo de produção com a utilização de cobertura morta com capim nas ruas da videira 'Niagara Rosada' e à dificuldade para sua aquisição, objetivou-se a possibilidade de substituí-la por plantas de cobertura intercalares. Em experimentos realizados em Indaiatuba e Jundiaí-SP, de 1999-2000 a 2003-2004, instalaram-se seis tratamentos nas entrelinhas, em blocos ao acaso e quatro repetições, constando de área no limpo; vegetação espontânea roçada; cobertura com capim seco de Brachiaria decumbens; cobertura verde de aveia preta (Avena strigosa); cobertura verde de chícharo (Lathyrus sativus); cobertura verde de tremoço (Lupinus albus), de março a outubro, seguidas de cobertura verde de mucuna anã (Mucuna deeringiana) de outubro a março. Determinaram-se massa, comprimento e largura do cacho, engaço e bagas, número total de bagas por cacho e diâmetro do pedicelo de bagas, comparando-se os valores médios pelo teste de Duncan ao nível de 5\%. Na média dos anos, os resultados com a cobertura verde foram similares ou mais favoráveis que os da cobertura com braquiária seca, podendo-se substituí-la por coberturas vegetais intercalares com gramínea e leguminosas, o ano todo, sem interferência negativa na qualidade comercial dos frutos.
\end{abstract}

Termos para indexação: Vitis sp., manejo do solo, cacho de uva, qualidade do fruto.

\section{INFLUENCE OF SOIL COVER WITH GRASS AND LEGUMINOUS PLANTS ON FRUIT CHARACTERISTICS OF TABLE GRAPE VARIETY NIAGARA ROSADA}

ABSTRACT - Grape vineyard in Southern Brazil utilize a large amount of mulch during autumn-winter season demanding extra efforts and costs, being its acquisition very difficult nowadays. In order to evaluate the possibility of replacing the tradicionally mulch by green cover species in the inter-row strip, two experiments were carried out in Indaiatuba and Jundiaí, SP, Brazil, from 1999/00 to 2003/04, with the table variety Niagara Rosada. The experimental design was a randomized block with four replications and six treatments: 1) no weeded area; 2) cut spontaneous local vegetation; 3) mulch of Brachiaria decumbens; 4) green cover of Avena strigosa from March to October followed by green cover of Mucuna deeringiana from October to March; 5) green cover of Lathyrus sativus from March to October followed by green cover of M. deeringiana from October to March; and 6) Lupinus albus from March to October followed by green cover of $M$. deeringiana from October to March. The weight, lengh and width of cluster, rachis and berries of grape, the total number of berries and its pedicel diameter were evaluated. The average values were compared by Duncan test at the level of 5\%. The results of all characteristics obtained with the green cover crops were equal or more favorable than those ones using grass mulch cover ( $B$. decumbens), being possible to utilize green manure crops in the inter-rows of grape vineyard without any negative interference on some commercial characteristics of grape fruits.

Index terms: Vitis sp., soil management, grape cluster, fruit quality.

\section{INTRODUÇÃO}

O Estado de São Paulo é o maior produtor de uvas para mesa, com prevalência das 'Niagaras', em área de 7.626 ha, representando $66,3 \%$ dos vinhedos (Ghilardi e Maia, 2001). São tradicionalmente cultivadas por pequenos a médios produtores, em áreas médias de 10 ha, sobretudo nas regiões circunvizinhas aos municípios de Jundiaí, Louveira e Indaiatuba, com predominância de mão-de-obra familiar, em sistema de meação, e garantia de sustento de inúmeras famílias (Pommer et al., 1998; Amaro, 2002).

A exigência em "qualidade" é evidente nos mercados externo e interno, e os requisitos mínimos referem-se ao tamanho e à uniformidade dos cachos - massa, e bagas - calibre; à aparência, aroma e sabor, dentre outros (Benato, 2003). Ainda, é desejável a manutenção da qualidade do produto, já que uvas ácidas ou degranadas não são aceitas pelos consumidores (Amaro, 2002).

A utilização de cobertura morta nas ruas, com restos vegetais, como capim-gordura, bagaço de cana-de-açúcar e serragem, dentre outros, é um dos tratos culturais comuns no vinhedo, sobretudo para a prevenção e o controle da erosão e do mato e manutenção de umidade e temperatura adequadas no perfil do solo (Sousa et al., 1996; Pommer et al., 1998; Terra et al., 1998), com resultados distintos na produtividade. Entretanto, recentemente, tem sido constatada a elevada magnitude do custo dessa forração, cuja adoção e prática resultaram em aumento nos desembolsos dos proprietários (Ghilardi e Maia, 2001), motivando-os à utilização de alternativas, como adubação verde intercalar, que pode ser igualmente vantajosa (Wutke, 2001). Além disso, a dificuldade atual de obtenção dessa matéria-prima é também preocupante. Ainda, em algumas situações, os agricultores também utilizam a vegetação espontânea local, roçada periodicamente, ou mantém a área nas entrelinhas totalmente no limpo.

Estudos dessa natureza ainda são quase inexistentes no Brasil, tendo sido obtidos alguns resultados preliminares favoráveis, com possibilidade de utilização da adubação verde sem prejuízos à qualidade dos frutos de 'Niagara Rosada', quanto ao pH; aos teores de sólidos solúveis totais, em ${ }^{\circ}$ Brix; à acidez total titulável, e à relação entre ambos (Wutke et al., 2004). Em Louveira-SP, após um ano de adubação verde com leguminosas, em ruas alternadas do parreiral, no outono-inverno, produziram-se frutos com bagas maiores, firmes e com casca mais grossa, o que é interessante ao transporte e comercialização da uva (Manera, 1986).

Assim, no presente estudo, objetivou-se avaliar diferentes coberturas vegetais intercalares em sucessão, no parreiral, durante o ano, em substituição sobretudo à cobertura morta tradicional com capim, e seu efeito em algumas características qualitativas dos frutos de uva de mesa 'Niagara Rosada', relacionadas à sua comercialização, tais como massa e dimensões de comprimento e largura do cacho, engaço e baga, além do número total de bagas por cacho e do diâmetro do pedicelo da baga.

\footnotetext{
(Trabalho 069/2005). Recebido: 20/04/2005. Aceito para publicação: 10/11/2005. Com recursos parciais do Tesouro do Estado, FAPESP e PRONAF/1999. Trabalho apresentado no XVIII Congresso Brasileiro de Fruticultura, de 22 a 26-11-2004, em Florianópolis-SC, com apoio da FAPESP.

2 Pesquisadores científicos, Instituto Agronômico - IAC; Caixa Postal 28; 13001-970 Campinas-SP. Endereços eletrônicos: ebwutke@iac.sp.gov.br; mmterra@iac.sp.gov.br; ejppires@iac.sp.gov.br; ivanribe@terra.com.br.

${ }^{3}$ Engenheiro Agrônomo, Mestre, estagiário; Instituto Agronômico - IAC.

${ }^{4}$ Engenheiro Agrônomo, Sindicato Rural de Indaiatuba-SP. Endereço eletrônico: isecco@uol.com.br
} 


\section{MATERIAL E MÉTODOS}

Dois experimentos com 'Niagara Rosada', enxertada sobre IAC766 ‘Campinas', foram instalados em Indaiatuba e Jundiaí-SP, em regiões com clima do tipo Cwa - tropical de altitude e solos Cambissolos latossólicos, com fertilidade média a elevada durante todos os anos da experimentação. Ao início desta e, conforme os resultados das análises, constataram-se valores respectivos, em Indaiatuba e Jundiaí, de 28 e $18 \mathrm{~g} . \mathrm{dm}^{-3}$ de matéria orgânica; 5 e 5,2 de pH; 46 e $67 \%$ de saturação por bases -V\%; 102 e $155 \mathrm{mg}_{\text {.dm }}{ }^{-3}$ de P e 2,9 e 9,3 de K; 38 e 35 de Ca e 4 e 15 de $\mathrm{Mg}$, estes três últimos em mmol $\cdot \mathrm{dm}^{-3}$.

Os parreirais estavam conduzidos em espaldeira, com cobertura morta de capim Brachiaria decumbens. Os experimentos foram iniciados em abril de 1999, em parreiral de 1,5 ano de idade, no espaçamento de $1,7 \mathrm{~m} \times 1 \mathrm{~m}$, em Indaiatuba, e de 8 anos, com $2 \mathrm{~m} \times 1 \mathrm{~m}$, em Jundiaí.

O delineamento experimental foi o de blocos ao acaso, com seis tratamentos e quatro repetições, num total de 24 parcelas, avaliadas por cinco e três anos agrícolas, respectivamente, em Indaiatuba e Jundiaí. A distribuição dos tratamentos nas entrelinhas do parreiral, em cada bloco, foi realizada no primeiro ano e mantida em todos os anos da experimentação, em ambos os locais. Os tratamentos foram: 1) no limpo o ano todo; 2) cobertura com vegetação espontânea do local, roçada quando necessário; 3 ) cobertura morta com capim seco de $B$. decumbens o ano todo; 4) cobertura verde com aveia-preta (Avena strigosa) de março/abril a outubro e com mucuna-anã (Mucuna deeringiana) de outubro a março; 5) cobertura verde com chícharo (Lathyrus sativus) de março/abril a outubro e com mucuna-anã de outubro a março; 6) cobertura verde com tremoço-branco (Lupinus albus) de março/abril a outubro e com mucuna-anã de outubro a março. As espécies cultivadas de março a outubro foram destinadas à produção de sementes, e a mucuna-anã foi roçada no pleno florescimento das plantas. No tratamento 2, a vegetação espontânea foi composta, predominantemente, por picãopreto (Bidens pilosa), nabiça (Raphanus raphanistrum) e amendoimbravo (Euphorbia heteroplylla), em Indaiatuba e, por tiririca (Cyperus rotundus), picão-branco (Galinsoga parviflora), beldroega (Portulaca oleracea) e caruru (Amaranthus deflexus), em Jundiaí.

Cada canteiro foi constituído por duas e três linhas da videira, com $8 \mathrm{~m}$ de comprimento, em Indaiatuba e Jundiaí, respectivamente, em áreas de $16 \mathrm{~m}^{2} \mathrm{e} 32 \mathrm{~m}^{2}$. Nas ruas, foram semeadas, sem adubação, quatro linhas de chícharo, tremoço e mucuna-anã, espaçadas $0,5 \mathrm{~m}$ entre si, com 15 sementes/m e sete linhas de aveia-preta, com $0,25 \mathrm{~m}$ entre si, com 40 sementes $/ \mathrm{m}$.

Realizaram-se duas a três colheitas parciais por safra e local, de dezembro a janeiro de 1999-2000, 2000-2001, 2001-2002, além das safras de 2002-2003 e 2003-2004 em Indaiatuba. No canteiro, colheramse todos os frutos de seis plantas, amostrando-se aleatoriamente dois cachos de uva/ planta, num total de 12 cachos/canteiro. Avaliaram-se massa, comprimento e largura do cacho e engaço. As bagas foram destacadas dos engaços, determinado-se seu número total e, em amostras aleatórias de dez bagas/cacho, determinaram-se massa, comprimento e largura da baga e diâmetro do pedicelo, utilizando-se de balança de precisão e paquímetro digitais. Os dados obtidos nos dois experimentos foram comparados por safra, em cada local e conjuntamente nos anos, para cada local, pelo teste de Duncan, ao nível de $5 \%$.

Ainda, para fins comparativos no trabalho e devido à quase inexistência de padrões de referência estabelecidos para qualidade de frutos de 'Niagara Rosada', adotaram-se critérios de regulamentos técnicos de identidade e qualidade para a classificação de uvas finas de mesa e uvas rústicas relacionados em Instrução Normativa (BRASIL, 2002; Benato, 2003).

\section{RESULTADOS E DISCUSSÃO}

Os resultados médios por safra e local, dos frutos de videira 'Niagara Rosada', referentes às massas do cacho e do engaço, estão na Tabela 1; os de comprimento e largura de cacho, na Tabela 2; o n ${ }^{\circ}$ total de bagas/cacho e da massa média de dez bagas/cacho, na Tabela 3; os de comprimento e largura de engaço, na Tabela 4; os de comprimento e largura de bagas, na Tabela 5, e os de diâmetro de pedicelo das bagas de uva, na Tabela 6 .

Nas análises individuais, por safra, em Indaiatuba, observaramse efeitos significativos entre tratamentos para largura de cacho, em 1999-2000 (Tabela 2), massa de dez bagas, em 1999-2000 (Tabela 3), e comprimento e largura de engaço, em 2001-2002 (Tabela 4). Em Jundiaí, apenas para massa do cacho, em 2000-2001 e 2001-2002, massa do engaço, em 2001-2002, e na massa de 10 bagas, em 2001-2002. Ainda, as diferenças constatadas entre os tratamentos, sobretudo para parâmetros quantitativos em Jundiaí - massa de cacho nas duas últimas safras e massa de bagas na mesma e última safra, possivelmente estejam

TABELA 1 - Massa de cacho e de engaço de uva Niagara Rosada. Indaiatuba, safras de 1999-2000 a 2003-2004 e Jundiaí, safras de $1999-2000$ a 2001 2002 - SP.

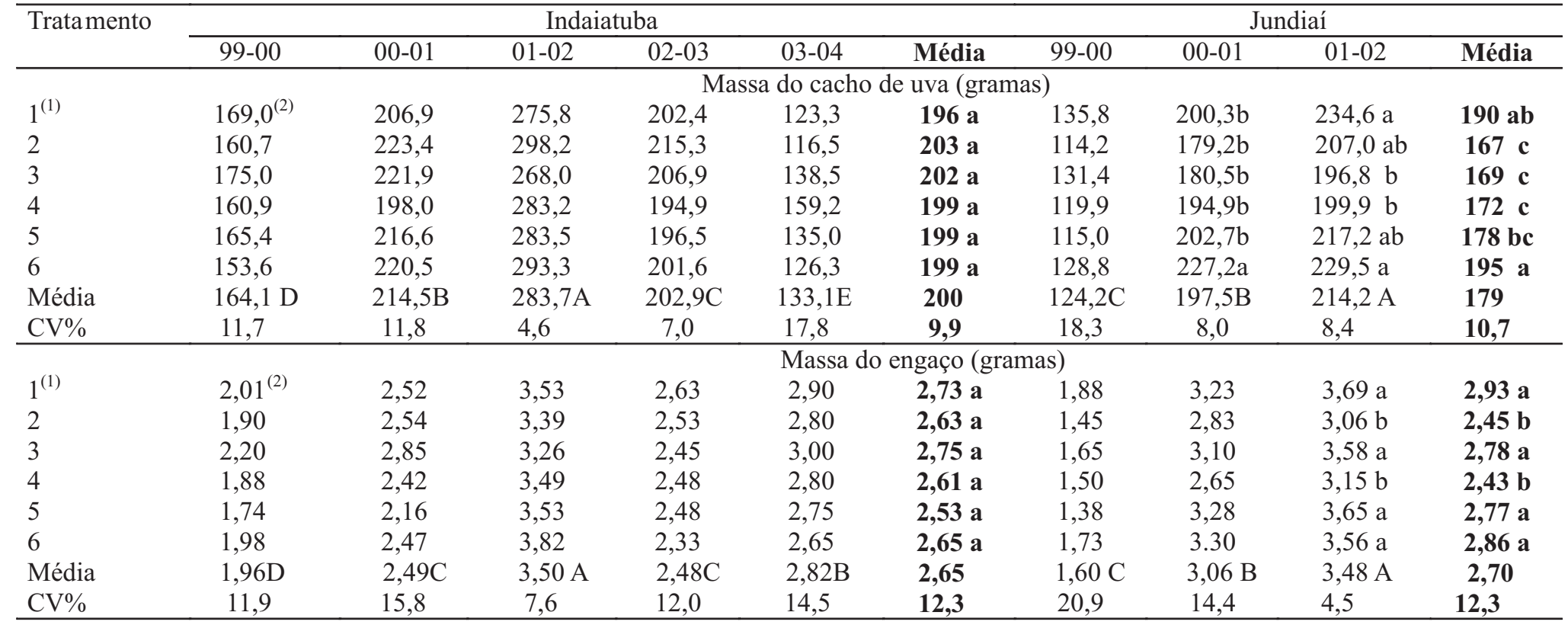

(1)1: Entrelinhas no limpo; 2: Mato roçado; 3:Capim seco de braquiária; 4: Aveia-preta/mucuna-anã; 5: Chícharo/mucuna-anã; 6: Tremoço/mucuna-anã; (2) Média de 48 dados. Médias seguidas pelas mesmas letras minúsculas nas colunas e maiúsculas nas linhas não são diferentes entre si, pelo teste de Duncan, a $5 \%$. 
TABELA 2 - Comprimento e largura de cacho de uva Niagara Rosada. Indaiatuba, safras de 1999-2000 a 2003-2004 e Jundiaí, safras de $1999-2000$ a 2001-2002 - SP.

\begin{tabular}{|c|c|c|c|c|c|c|c|c|c|c|}
\hline \multirow[t]{2}{*}{ Tratamento } & \multicolumn{6}{|c|}{ Indaiatuba } & \multicolumn{4}{|c|}{ Jundiaí } \\
\hline & $99-00$ & $00-01$ & $01-02$ & $02-03$ & $03-04$ & Média & $99-00$ & $00-01$ & $01-02$ & Média \\
\hline & \multicolumn{10}{|c|}{ Comprimento do cacho de uva $(\mathrm{cm})$} \\
\hline $1^{(1)}$ & $13,3^{(2)}$ & 12,1 & 15,5 & 12,8 & 14,6 & 13,6 a & 12,1 & 13,0 & 14,3 & 13,1 a \\
\hline 2 & 13,3 & 12,6 & 15,3 & 13,2 & 14,5 & 13,8 a & 11,4 & 12,9 & 13,7 & $12,6 \mathrm{a}$ \\
\hline 3 & 13,8 & 12,8 & 15,0 & 12,9 & 14,4 & 13,8 a & 11,5 & 12,8 & 14,0 & $12,8 \mathrm{a}$ \\
\hline 4 & 13,4 & 12,0 & 16,1 & 13,4 & 14,4 & 13,9 a & 10,8 & 12,7 & 14,1 & $12,5 \mathrm{a}$ \\
\hline 5 & 12,8 & 11,6 & 16,2 & 13,0 & 14,6 & 13,7 a & 10,7 & 13,1 & 14,1 & $12,6 \mathrm{a}$ \\
\hline 6 & 13,3 & 12,2 & 16,5 & 13,3 & 14,3 & 13,9 a & 11,5 & 13,2 & 14,4 & 13,0 a \\
\hline Média & $13,3 \mathrm{C}$ & $12,2 \mathrm{D}$ & $15,8 \mathrm{~A}$ & $13,1 \mathrm{C}$ & $14,5 \mathrm{~B}$ & 13,8 & $11,3 \mathrm{C}$ & $12,9 \mathrm{~B}$ & $14,1 \mathrm{~A}$ & 12,8 \\
\hline \multirow{2}{*}{ CV\% } & 3,1 & 6,3 & 4,9 & 4,1 & 2,4 & 4,3 & 8,8 & 5,1 & 3,4 & 5,8 \\
\hline & \multicolumn{10}{|c|}{ Largura do cacho de uva $(\mathrm{cm})$} \\
\hline $1^{(1)}$ & $8,3 \mathrm{a}^{(2)}$ & 8,1 & 8,7 & 7,6 & 8,5 & 8,2 a & 8,2 & 7,9 & 8,4 & 8,2 a \\
\hline 2 & $7,8 \mathrm{~b}$ & 8,2 & 9,1 & 7,6 & 8,2 & 8,2 a & 7,4 & 7,4 & 8,3 & $7,7 \mathbf{a}$ \\
\hline 3 & $8,2 \mathrm{a}$ & 8,2 & 8,6 & 7,4 & 8,6 & 8,2 a & 7,6 & 7,6 & 8,3 & 7,8 a \\
\hline 4 & $7,6 \mathrm{~b}$ & 7,7 & 9,1 & 7,6 & 8,1 & 8,0 a & 7,2 & 7,8 & 8,2 & $7,7 \mathbf{a}$ \\
\hline 5 & $7,5 \mathrm{~b}$ & 7,6 & 9,4 & 7,6 & 8,6 & 8,1 a & 7,1 & 8,0 & 7,9 & $7,7 \mathbf{a}$ \\
\hline 6 & $8,1 \mathrm{ab}$ & 7,8 & 9,5 & 7,5 & 7,8 & 8,1 a & 7,5 & 7,9 & 8,1 & 7,8 a \\
\hline Média & 7,9 C & 7,9 C & $9,1 \mathrm{~A}$ & 7,6 D & $8,3 \mathrm{~B}$ & 8,1 & 7,5 C & 7,8 B & $8,2 \mathrm{~A}$ & 7,8 \\
\hline CV\% & 3,8 & 4,1 & 4,6 & 3,7 & 7,6 & 5,0 & 7,6 & 6,1 & 4,8 & 6,2 \\
\hline
\end{tabular}

(1) 1: Entrelinhas no limpo; 2: Mato roçado; 3:Capim seco de braquiária; 4: Aveia-preta/mucuna-anã; 5: Chícharo/mucuna-anã; 6: Tremoço/mucuna-anã; (2) Média de 48 dados. Médias seguidas pelas mesmas letras minúsculas nas colunas e maiúsculas nas linhas não são diferentes entre si, pelo teste de Duncan, a 5\%.

relacionadas ao menor teor de matéria orgânica constatado inicialmente nessa localidade - $18 \mathrm{~g} . \mathrm{dm}^{-3}$, bastante inferior aos $28 \mathrm{~g} . \mathrm{dm}^{-3}$, em Indaiatuba, onde não se obteve tal discriminação. Assim, com a utilização continuada nos anos de cobertura verde intercalar, podem-se esperar reposição e manutenção da matéria orgânica em condições de solos com teor reduzido da mesma, com conseqüente contribuição para a fertilidade do solo e obtenção de efeitos favoráveis na videira, conforme enfatizado por alguns autores (Manera, 1986; Sousa, 1996; Sousa et al., 1996; Wutke, 2001).

Nas análises conjuntas por local, e considerando-se os valores médios de 240 e 144 cachos, respectivamente em cinco safras em Indaiatuba e em três safras em Jundiaí, houve diferença significativa para todos os parâmetros, entre as safras, em cada local, com destaque para os de 2001-2002, na maioria dos parâmetros avaliados e em ambas as localidades (Tabelas 1 a 6). Diante disso, evidenciou-se a influência nítida das condições climáticas nos distintos anos, e não das diferentes coberturas verdes utilizadas, da vegetação espontânea roçada ou das ruas mantidas no limpo, além da própria cobertura de capim seco. Entre tratamentos, houve diferença estatística apenas em Jundiaí, e para massa do cacho, e massa e largura do engaço. Nas interações safras $\mathrm{x}$ tratamentos, observou-se significância em Indaiatuba, para massa de bagas, e comprimento e largura do engaço. Em Jundiaí, estas foram para a massa do cacho e de bagas, particularmente em safras mais favoráveis, e na largura de engaço. Comparativamente à utilização da cobertura morta com capim, Wutke et al. (2004) também não constataram interferência negativa da adubação verde intercalar na qualidade dos frutos de 'Niagara Rosada', especificamente no $\mathrm{pH}$, nos teores de sólidos solúveis totais, expressos em ${ }^{\circ}$ Brix; na acidez total titulável nem na relação entre ambos.

Assim, considerando-se os valores médios de cinco safras em Indaiatuba e de três safras em Jundiaí, e em relação ao tratamento tradicional de cobertura de capim seco de braquiária, considerada como testemunha no estudo, os resultados em parâmetros de relevância à qualidade do fruto, tais como tamanho e dimensões do cacho e das

TABELA 3 - Número total de bagas por cacho e massa média de 10 bagas por cacho de uva Niagara Rosada. Indaiatuba, safras de $1999-2000$ a 2003 2004 e Jundiaí, safras de 1999-2000 a 2001-2002 - SP

\begin{tabular}{|c|c|c|c|c|c|c|c|c|c|c|}
\hline \multirow[t]{2}{*}{ Tratamento } & \multicolumn{6}{|c|}{ Indaiatuba } & \multicolumn{4}{|c|}{ Jundiaí } \\
\hline & $99-00$ & $00-01$ & $01-02$ & $02-03$ & 03-04 & Média & $99-00$ & $00-01$ & $01-02$ & Média \\
\hline & \multicolumn{10}{|c|}{ Total de bagas de uva por cacho (número) } \\
\hline $1^{(1)}$ & $66^{(2)}$ & 56 & 72 & 69 & 67 & $66 \mathrm{a}$ & 54 & 57 & 74 & 62 a \\
\hline 2 & 62 & 59 & 72 & 69 & 67 & 66 a & 41 & 51 & 69 & 54 a \\
\hline 3 & 72 & 62 & 74 & 67 & 69 & $69 a$ & 42 & 56 & 68 & 55 a \\
\hline 4 & 63 & 53 & 75 & 63 & 66 & $64 a$ & 38 & 53 & 71 & 54 a \\
\hline 5 & 63 & 50 & 75 & 65 & 65 & $63 a$ & 36 & 58 & 72 & 55 a \\
\hline 6 & 66 & 56 & 77 & 66 & 62 & $65 a$ & 42 & 59 & 71 & 58 a \\
\hline Média & $65 \mathrm{~B}$ & $56 \mathrm{C}$ & $74 \mathrm{~A}$ & $66 \mathrm{~B}$ & $66 \mathrm{~B}$ & 65 & $42 \mathrm{C}$ & $55 \mathrm{~B}$ & $71 \mathrm{~A}$ & 56 \\
\hline \multirow[t]{2}{*}{ CV\% } & 7,9 & 10,9 & 6,8 & 5,8 & 10,4 & 8,4 & 21,0 & 10,4 & 11,7 & 13,8 \\
\hline & \multicolumn{10}{|c|}{ Massa média de 10 bagas de uva por cacho (gramas) } \\
\hline $1^{(1)}$ & $41,6 \mathrm{a}^{(2)}$ & 49,4 & 45,9 & 43,6 & 46,5 & 45,4 a & 40,4 & 46,9 & $41,0 \mathrm{abc}$ & 42,7 a \\
\hline 2 & $42,0 \mathrm{a}$ & 49,0 & 48,2 & 44,0 & 45,9 & 45,8 a & 39,5 & 47,2 & $42,5 \mathrm{a}$ & 43,1 a \\
\hline 3 & $40,6 \mathrm{ab}$ & 49,3 & 47,6 & 44,2 & 47,3 & 45,8 a & 40,1 & 44,0 & $36,7 \mathrm{~d}$ & 40,3 a \\
\hline 4 & $39,3 \mathrm{ab}$ & 48,8 & 47,3 & 45,3 & 47,5 & 45,7 a & 40,7 & 46,8 & $39,4 \mathrm{bc}$ & 42,3 a \\
\hline 5 & $38,0 \mathrm{~b}$ & 48,4 & 48,8 & 43,9 & 46,5 & 45,1 a & 40,9 & 46,7 & $38,5 \mathrm{~cd}$ & $42,1 \mathrm{a}$ \\
\hline 6 & $40,2 \mathrm{ab}$ & 47,6 & 51,0 & 42,1 & 45,6 & 45,3 a & 41,1 & 45,2 & $41,1 \mathrm{ab}$ & 42,5 a \\
\hline Média & $40,3 \mathrm{D}$ & $48,7 \mathrm{~A}$ & $48,1 \mathrm{~A}$ & $43,8 \mathrm{C}$ & $46,5 \mathrm{~B}$ & 45,5 & $40,4 \mathrm{~B}$ & $46,1 \mathrm{~A}$ & 39,9 B & 42,1 a \\
\hline $\mathrm{CV} \%$ & 4,1 & 2,3 & 6,6 & 4,5 & 3,1 & 4,4 & 5,4 & 4,5 & 3,9 & 4,7 \\
\hline
\end{tabular}

(1) 1: Entrelinhas no limpo; 2: Mato roçado; 3: Capim seco; 4: Aveia-preta/mucuna-anã; 5: Chícharo/mucuna-anã; 6: Tremoço/mucuna-anã; (2) Média de 48 dados. Médias seguidas pelas mesmas letras minúsculas nas colunas e maiúsculas nas linhas não são diferentes entre si, pelo teste de Duncan, a $5 \%$. 
TABELA 4 - Comprimento e largura do engaço de uva Niagara Rosada. Indaiatuba, safras de 1999-2000 a 2003-2004 e Jundiaí, safras de $1999-2000$ a 2001-2002 - SP.

\begin{tabular}{|c|c|c|c|c|c|c|c|c|c|c|}
\hline \multirow[t]{2}{*}{ Tratamento } & \multicolumn{6}{|c|}{ Indaiatuba } & \multicolumn{4}{|c|}{ Jundiaí } \\
\hline & $99-00$ & $00-01$ & $01-02$ & $02-03$ & $03-04$ & Média & $99-00$ & $00-01$ & $01-02$ & Média \\
\hline & \multicolumn{10}{|c|}{ Comprimento de engaço $(\mathrm{cm})$} \\
\hline $1^{(1)}$ & $10,6^{(2)}$ & 8,8 & $11,8 \mathrm{~d}$ & 9,2 & 11,0 & 10,3 a & 9,6 & 10,1 & 11,1 & 10,3 a \\
\hline 2 & 10,4 & 8,8 & $12,0 \mathrm{ab}$ & 10,0 & 10,9 & 10,4 a & 8,6 & 10,1 & 11,5 & 10,1 a \\
\hline 3 & 10,9 & 9,5 & $11,9 \mathrm{~cd}$ & 9,4 & 11,2 & 10,6 a & 8,8 & 10,4 & 10,9 & 10,1 a \\
\hline 4 & 10,1 & 8,3 & $12,9 \mathrm{ab}$ & 9,6 & 10,9 & 10,3 a & 8,2 & 10,3 & 11,2 & $9,9 \mathbf{a}$ \\
\hline 5 & 10,2 & 8,4 & $12,8 \mathrm{abc}$ & 9,4 & 11,2 & $10,4 \mathrm{a}$ & 8,0 & 10,2 & 11,0 & $9,7 \mathbf{a}$ \\
\hline 6 & 10,3 & 9,0 & 13,1 a & 9,7 & 11,0 & 10,6 a & 8,8 & 10,8 & 8,9 & $9,5 \mathbf{a}$ \\
\hline Média & $10,4 \mathrm{C}$ & $8,8 \mathrm{E}$ & $12,4 \mathrm{~A}$ & $9,5 \mathrm{D}$ & $11,0 \mathrm{~B}$ & 10,4 & $8,7 \mathrm{~B}$ & $10,3 \mathrm{~A}$ & $10,8 \mathrm{~A}$ & 9,9 \\
\hline \multirow[t]{2}{*}{ CV\% } & 4,6 & 10,0 & 4,8 & 5,6 & 3,8 & 5,8 & 11,3 & 5,4 & 19,9 & 14,1 \\
\hline & \multicolumn{10}{|c|}{ Largura de engaço $(\mathrm{cm})$} \\
\hline $1^{(1)}$ & 4,3 & 4,2 & $4,8 \mathrm{~b}$ & 3,6 & 4,6 & $4,3 \mathrm{a}$ & $4,5 \mathrm{a}$ & 4,8 & 4,7 & $4,6 \mathrm{ab}$ \\
\hline 2 & 3,8 & 4,3 & $4,0 \mathrm{~b}$ & 3,5 & 4,6 & 4,2 a & $3,9 \mathrm{ab}$ & 4,7 & 4,6 & $4,4 \mathrm{ab}$ \\
\hline 3 & 4,1 & 4,4 & $4,9 \mathrm{~b}$ & 3,4 & 4,3 & $4,2 \mathrm{a}$ & $4,2 \mathrm{ab}$ & 5,3 & 5,0 & 4,8 a \\
\hline 4 & 3,9 & 4,2 & $5,3 \mathrm{ab}$ & 3,6 & 4,3 & 4,3 a & $4,0 \mathrm{ab}$ & 4,9 & 5,0 & 4,6 ab \\
\hline 5 & 3,9 & 3,9 & $5,8 \mathrm{a}$ & 3,4 & 4,5 & 4,3 a & $3,6 \quad b$ & 4,4 & 4,8 & $4,2 \quad b$ \\
\hline 6 & 4,1 & 4,1 & $5,7 \mathrm{a}$ & 3,8 & 4,4 & $4,4 \mathrm{a}$ & $4,2 \mathrm{ab}$ & 5,0 & 4,8 & 4,6 ab \\
\hline Média & $4,0 \mathrm{C}$ & $4,2 \mathrm{C}$ & $5,3 \mathrm{~A}$ & $3,5 \mathrm{D}$ & 4,4 B & 4,3 & $4,0 \mathrm{~B}$ & $4,8 \mathrm{~A}$ & $4,8 \mathrm{~A}$ & 4,6 \\
\hline CV\% & 5,9 & 9,3 & 8,1 & 10,2 & 9,9 & 8,8 & 12,8 & 11,8 & 12,1 & 12,2 \\
\hline
\end{tabular}

(1) 1: Entrelinhas no limpo; 2: Mato roçado; 3: Capim seco; 4: Aveia-preta/mucuna-anã; 5: Chícharo/mucuna-anã; 6: Tremoço/mucuna-anã; (2) Média de 48 dados. Médias seguidas pelas mesmas letras minúsculas nas colunas e maiúsculas nas linhas não são diferentes entre si, pelo teste de Duncan, a 5\%.

bagas (Benato, 2003), obtidos com as coberturas verdes, sobretudo com a de tremoço seguida de mucuna-anã, em ambos os locais, foram, em sua maioria, estatisticamente similares ou superiores.

Ainda, foi verificada nítida influência do ambiente nos resultados, já que as diferenças foram entre safras. O clima é importante fator relacionado à duração do ciclo, à qualidade do produto, à fitossanidade e à produtividade da videira (Sentelhas \& Pereira, 1997), sendo a qualidade dos frutos bastante influenciada pela luminosidade/ radiação, água e temperatura do ar (Sousa, 1996). Na videira, são consideradas ótimas as temperaturas entre $10^{\circ} \mathrm{C}$ e $13^{\circ} \mathrm{C}$ na brotação, $15^{\circ} \mathrm{C}$ e $25^{\circ} \mathrm{C}$ no desenvolvimento vegetativo, florescimento e desenvolvimento da baga, e entre $20^{\circ} \mathrm{C} \mathrm{e} 30^{\circ} \mathrm{C}$ na maturação dos frutos (Pedro Júnior et al., 1993). De maneira geral, essas condições foram observadas em ambos os locais, situados na região de Jundiaí, durante o período considerado (Tabela 7).

Em relação à quantidade de água, são necessários $240 \mathrm{~mm}$ a $384 \mathrm{~mm}$ durante o ciclo da videira, sendo $94 \mathrm{~mm}$ da brotação até o início da floração, $25 \mathrm{~mm}$ da floração à fecundação, $135 \mathrm{~mm}$ da fecundação ao início do amadurecimento e $130 \mathrm{~mm}$ do amadurecimento à maturação (Gobbato, 1940). Conforme os dados da Tabela 4, da poda até a colheita dos frutos, essas condições foram verificadas, até mesmo além das necessidades da cultura, como nos anos de 2000, 2001 e 2003, sem prejuízo à qualidade do produto. Em 1999, quando a maioria da média dos valores foi significativamente menor, em ambos os locais, embora a quantidade total de chuvas tenha sido satisfatória, sua distribuição foi irregular no período.

Quanto às características dos frutos, e considerando-se os valores médios obtidos nas safras, nas duas localidades, o Grupo é Rosada; Subgrupo uniforme; os cachos são da Classe 2 ou calibre 150, com massa entre $150 \mathrm{~g}$ e $250 \mathrm{~g}$, à exceção da safra de 2001-2002 em Indaiatuba, com cachos maiores, da classe 3 ou calibre 350 , entre $250 \mathrm{~g}$ e $350 \mathrm{~g}$ (BRASIL, 2002; Benato, 2003).

O tamanho dos cachos é característica dependente do ambiente, e baseando-se em escala de Bioletti, citado em Sousa (1996),

TABELA 5 - Comprimento e largura de bagas de uva Niagara Rosada. Indaiatuba, safras de 1999-2000 a 2003-2004 e Jundiaí, safras de 1999-2000 a 2001-2002-SP.

\begin{tabular}{|c|c|c|c|c|c|c|c|c|c|c|}
\hline \multirow[t]{2}{*}{ Tratamento } & \multicolumn{6}{|c|}{ Indaiatuba } & \multicolumn{4}{|c|}{ Jundiaí } \\
\hline & 99-00 & 00-01 & 01-02 & $02-03$ & 03-04 & Média & $99-00$ & $00-01$ & $01-02$ & Média \\
\hline & \multicolumn{10}{|c|}{ Comprimento de baga de uva (mm) } \\
\hline $1^{(1)}$ & $19,9^{(2)}$ & 19,6 & 20,7 & 20,3 & 20,1 & 19,9 a & 18,7 & 19,2 & 19,1 & 19,0 a \\
\hline 2 & 19,1 & 19,6 & 20,5 & 20,0 & 20,0 & 19,9 a & 18,4 & 19,2 & 18,8 & 18,8 a \\
\hline 3 & 19,1 & 20,0 & 20,6 & 20,2 & 20,2 & 20,0 a & 18,6 & 18,8 & 19,1 & 18,9 a \\
\hline 4 & 18,5 & 19,5 & 20,3 & 20,1 & 20,5 & 19,8 a & 18,5 & 19,2 & 18,6 & 18,8 a \\
\hline 5 & 18,5 & 19,3 & 20,6 & 20,2 & 20,3 & 19,8 a & 18,8 & 19,0 & 18,8 & 18,9 a \\
\hline 6 & 18,7 & 19,4 & 20,5 & 19,9 & 20,2 & 19,8 a & 18,5 & 18,6 & 18,7 & 18,6 a \\
\hline Média & $18,8 \mathrm{D}$ & $19,6 \mathrm{C}$ & $20,5 \mathrm{~A}$ & $20,1 \mathrm{~B}$ & $20,2 \mathrm{~B}$ & 19,8 & $18,6 \mathrm{~B}$ & $19,0 \mathrm{~A}$ & $18,8 \mathrm{AB}$ & 18,8 \\
\hline \multirow[t]{2}{*}{$\mathrm{CV} \%$} & 2,8 & 2,4 & 1,1 & 2,1 & 2,8 & 2,3 & 2,0 & 2,7 & 3,1 & 2,6 \\
\hline & \multicolumn{10}{|c|}{ Largura de baga de uva (mm) } \\
\hline $1^{(1)}$ & $16,9^{(2)}$ & 16,8 & 18,5 & 18,0 & 18,0 & 17,6 a & 17,0 & 15,9 & 17,2 & 16,7 a \\
\hline 2 & 17,0 & 17,1 & 18,6 & 17,8 & 17,9 & $17,7 \mathbf{a}$ & 16,9 & 16,0 & 17,2 & 16,7 a \\
\hline 3 & 16,4 & 16,9 & 18,6 & 18,0 & 18,2 & 17,6 a & 17,1 & 15,7 & 17,0 & 16,6 a \\
\hline 4 & 16,8 & 16,9 & 18,6 & 17,9 & 18,3 & 17,7 a & 17,0 & 16,1 & 16,8 & 16,6 a \\
\hline 5 & 16,8 & 16,5 & 18,8 & 18,2 & 18,2 & $17,7 \mathbf{a}$ & 17,4 & 15,5 & 16,8 & 16,5 a \\
\hline 6 & 16,8 & 16,5 & 18,7 & 18,0 & 18,2 & 17,6 a & 17,1 & 15,6 & 16,8 & 16,5 a \\
\hline Média & $16,8 \mathrm{C}$ & $16,8 \mathrm{C}$ & $18,6 \mathrm{~A}$ & $18,0 \mathrm{~B}$ & $18,1 \mathrm{~B}$ & 17,7 & $17,1 \mathrm{~A}$ & $15,8 \mathrm{~B}$ & $17,0 \mathrm{~A}$ & 16,6 \\
\hline CV\% & 2,9 & 2,4 & 1,0 & 2,5 & 2,8 & 2,4 & 1,7 & 2,9 & 2,5 & 2,4 \\
\hline
\end{tabular}

(1) 1: Entrelinhas no limpo; 2: Mato roçado; 3: Capim seco; 4: Aveia-preta/mucuna-anã; 5: Chícharo/mucuna-anã; 6: Tremoço/mucuna-anã; (2) Média de 48 dados. Médias seguidas pelas mesmas letras minúsculas nas colunas e maiúsculas nas linhas não são diferentes entre si, pelo teste de Duncan, a 5\%. 
TABELA 6 - Diâmetro de pedicelo de bagas de uva Niagara Rosada. Indaiatuba, safras de 1999-2000 a 2003-2004 e Jundiaí, safras de 1999-2000 a 2001 2002 - SP.

\begin{tabular}{|c|c|c|c|c|c|c|c|c|c|c|}
\hline \multirow[t]{2}{*}{ Trata mento } & \multicolumn{6}{|c|}{ Indaiatuba } & \multicolumn{4}{|c|}{ Jundiaí } \\
\hline & $99-00$ & $00-01$ & $01-02$ & $02-03$ & $03-04$ & Média & $99-00$ & $00-01$ & $01-02$ & Média \\
\hline & \multicolumn{10}{|c|}{ Diâmetro do pedicelo de baga de uva (mm) } \\
\hline $1^{(1)}$ & $3,39^{(2)}$ & 3,63 & 3,29 & 3,28 & $3,39 \mathrm{ab}$ & 3,40 a & 4,16 & 3,86 & 3,23 & $3,75 \mathrm{a}$ \\
\hline 2 & 3,38 & 3,65 & 3,30 & 3,28 & 3,35 a & 3,39 a & 4,07 & 3,89 & 3,43 & $3,79 \mathrm{a}$ \\
\hline 3 & 3,32 & 3,67 & 3,34 & 3,30 & $3,42 a b$ & 3,41 a & 4,36 & 3,80 & 3,20 & 3,78 a \\
\hline 4 & 3,43 & 3,69 & 3,40 & 3,35 & $3,49 a b$ & 3,47 a & 4,01 & 3,88 & 3,03 & $3,64 \mathrm{a}$ \\
\hline 5 & 3,35 & 3,58 & 3,27 & 3,30 & 3,61 a & 3,42 a & 4,12 & 3,89 & 3,15 & $3,72 \mathrm{a}$ \\
\hline 6 & 3,29 & 3,60 & 3,32 & 3,28 & $3,55 a b$ & 3,41 a & 4,07 & 3,88 & 3,00 & 3,65 a \\
\hline Média & $3,36 \mathrm{C}$ & $3,63 \mathrm{~A}$ & $3,32 \mathrm{C}$ & $3,30 \mathrm{C}$ & $3,47 \mathrm{~B}$ & 3,42 & $4,13 \mathrm{~A}$ & $3,86 \mathrm{~B}$ & $3,17 \mathrm{C}$ & 3,72 \\
\hline CV\% & 4,4 & 4,0 & 2,9 & 4,3 & 4,1 & 4,0 & 5,4 & 3,7 & 8,8 & 6,0 \\
\hline
\end{tabular}

(1) 1: Entrelinhas no limpo; 2: Mato roçado; 3: Capim seco; 4: Aveia-preta/mucuna-anã; 5: Chícharo/mucuna-anã; 6: Tremoço/mucuna-anã; (2) Média de 48 dados. Médias seguidas pelas mesmas letras minúsculas nas colunas e maiúsculas nas linhas não são diferentes entre si, pelo teste de Duncan, a 5\%.

TABELA 7 - Valores médios de temperatura mínima (Tm), máxima (TM) e média (Tx) da região de Jundiaí-SP, e de precipitação pluvial desde a poda/ brotação até a maturação dos frutos da videira 'Niagara Rosada', em Indaiatuba e em Jundiaí-SP, em distintos anos agrícolas.

\begin{tabular}{|c|c|c|c|c|c|c|c|c|c|c|c|c|c|c|c|}
\hline \multirow{2}{*}{$\begin{array}{c}\text { Mês } \\
\text { do ano }\end{array}$} & \multicolumn{3}{|c|}{1999} & \multicolumn{3}{|c|}{2000} & \multicolumn{3}{|c|}{2001} & \multicolumn{3}{|c|}{2002} & \multicolumn{3}{|c|}{2003} \\
\hline & $\mathrm{Tm}$ & TM & $\mathbf{T x}$ & $\mathrm{Tm}$ & $\mathrm{TM}$ & $\mathbf{T x}$ & $\mathrm{Tm}$ & TM & $\mathbf{T x}$ & $\mathrm{Tm}$ & TM & $\mathbf{T x}$ & $\mathrm{Tm}$ & TM & $\mathrm{Tx}$ \\
\hline & & & & & $\cdots$ & 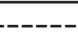 & Tempe & uras, $€$ & ${ }^{\circ} \mathrm{C}--$ & & $-\cdots$ & . & --- & -- & 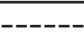 \\
\hline Jul. & 11,8 & 24,6 & 18,2 & 9,6 & 23,1 & 16,4 & 11,9 & 25,3 & 18,6 & 10,9 & 24,6 & 17,8 & 11,3 & 25,3 & 18,3 \\
\hline Ago. & 10,4 & 26,2 & 18,3 & 12,2 & 24,9 & 18,5 & 12,7 & 26,5 & 19,6 & 14,3 & 27,7 & 21,0 & 10,9 & 24,2 & 17,6 \\
\hline Set. & 13,3 & 27,2 & 20,2 & 14,7 & 26,0 & 20,4 & 14,3 & 26,0 & 20,2 & 13,4 & 26,0 & 19,7 & 14,0 & 35,0 & 24,5 \\
\hline Out. & 14,6 & 26,1 & 20,3 & 17,3 & 30,6 & 24,0 & 14,9 & 28,2 & 21,6 & 17,7 & 32,0 & 24,8 & 15,4 & 28,2 & 21,8 \\
\hline Nov. & 14,7 & 27,2 & 20,9 & 17,1 & 28,4 & 22,8 & 17,7 & 29,3 & 23,5 & 17,1 & 28,8 & 23,0 & 16,6 & 27,8 & 22,2 \\
\hline Dez. & 17,6 & 30,0 & 23,8 & 18,0 & 28,6 & 23,3 & 17,7 & 28,0 & 22,9 & 18,3 & 30,5 & 24,4 & 18,2 & 29,6 & 23,9 \\
\hline Mês & \multicolumn{10}{|c|}{ Indaiatuba } & \multicolumn{5}{|c|}{ Jundiaí } \\
\hline \multirow[t]{2}{*}{ do ano } & 1999 & & 2000 & \multicolumn{3}{|c|}{2001} & \multicolumn{2}{|c|}{2002} & \multicolumn{2}{|c|}{2003} & \multirow{2}{*}{\multicolumn{2}{|c|}{1999}} & & \multicolumn{2}{|c|}{2001} \\
\hline & \multicolumn{6}{|l|}{------------ } & ecipi & ão $\mathrm{pl}$ & $\mathrm{al}, \mathrm{em}$ & $\mathrm{nm} / \mathrm{m}$ & & & ---- & \multicolumn{2}{|c|}{---------- } \\
\hline Jul. & \multicolumn{2}{|l|}{7,0} & 111,0 & \multicolumn{3}{|c|}{31,0} & \multicolumn{2}{|c|}{14,0} & \multicolumn{2}{|c|}{47,0} & 1,5 & & 91,9 & \multicolumn{2}{|c|}{12,1} \\
\hline Ago. & \multicolumn{2}{|l|}{0} & 97,0 & \multicolumn{3}{|c|}{36,0} & 74 & & \multicolumn{2}{|c|}{22,5} & 0 & & 76,6 & \multicolumn{2}{|c|}{32,8} \\
\hline Set. & 106,0 & & 187,5 & \multicolumn{3}{|c|}{101,0} & 25 & & \multicolumn{2}{|c|}{35,0} & 102,6 & & 142,2 & \multicolumn{2}{|c|}{60,9} \\
\hline Out. & 41,5 & & 75,5 & \multicolumn{3}{|c|}{293,5} & 105 & & \multicolumn{2}{|c|}{104,0} & 60,5 & & 88,9 & \multicolumn{2}{|c|}{85,8} \\
\hline Nov. & 46,0 & & 253,0 & & 89,5 & & 179 & & & 7,0 & 53,0 & & 240,7 & & \\
\hline Dez. & 94,0 & & 219,5 & & 182,5 & & 127 & & & 3,0 & 88,8 & & 255,0 & & \\
\hline Total & 294,5 & & 943,5 & & 733,3 & & 525 & & & 8,5 & 306,4 & & 395,3 & & \\
\hline
\end{tabular}

Dados coletados no posto meteorológico na então Estação Experimental de Agronomia do Instituto Agronômico, em Jundiaí-SP, e no Sítio dos Meninos, em Indaiatuba-SP.

nas médias dos dois locais do presente estudo, os cachos podem ser considerados de massa pequena, entre $151 \mathrm{~g}$ e $250 \mathrm{~g}$, sendo médios entre $251 \mathrm{~g}$ e $800 \mathrm{~g}$, apenas na safra de 2001-2002, em Indaiatuba. Os valores foram superiores aos $171 \mathrm{~g}$ obtidos em nove anos de experimentação com 'Niagara Rosada', em Jundiaí-SP (Terra et al.,1988) e aos $143 \mathrm{~g}$, em Caldas-MG (Alvarenga, 2001), e inferiores aos de Botelho (2002), porém em apenas um ano em Jundiaí. Entretanto, o autor obteve valores inferiores aos da maioria das características do fruto avaliadas no presente trabalho.

Quanto ao comprimento, os cachos podem ser classificados como médios, por terem entre 12,1 cm e $18 \mathrm{~cm}$ (Queiroz-Voltan e Pires, 2003). As dimensões de comprimento e largura de cacho e largura de engaço são maiores do que as verificadas por Cato (2002), em duas safras, em Junqueirópolis-SP, porém com menor diâmetro de pedicelo.

Conforme classificação de Galet (1993), as bagas têm largura média - entre $13 \mathrm{~mm}$ e $18 \mathrm{~mm}$, e massa de 100 bagas grandes - entre 331 g e $700 \mathrm{~g}$, características bastante adequadas à comercialização do produto (Amaro, 2001; Benato, 2003).

\section{CONCLUSÕES}

A cobertura morta de capim nas ruas do parreiral pode ser substituída pelo cultivo de plantas para cobertura verde no outonoinverno, como aveia-preta, chícharo ou tremoço, seguidos de mucunaanã, na primavera-verão, sem alteração prejudicial em relevantes características comerciais de qualidade dos frutos de videira 'Niagara
Rosada', como tamanho e dimensões do cacho e das bagas.

\section{AGRADECIMENTOS}

Os autores agradecem a colaboração e expressam seus agradecimentos à Sra Maria Andinalva C. Secco, Srs. José Valdomiro Secco e Josué Carlos Secco, do Sítio dos Meninos, em Indaiatuba; aos meeiros João Razze, Paulo Colodiano e famílias; aos funcionários do Instituto Agronômico: Paulo Eduardo Magalhães, Valdeir Biúdes Hermoso, José Luiz Hernandes, Nereu P. Santos (falecido), Luzia Fátima da Silva, Tereza Sinotti, Amarildo C. da Silva, Nair Antônia dos Santos, Jorgina Laurentina Vaz, Ivanilda dos Santos, Ocimara Aparecida Alves, Douglas R. dos Santos, Marcelino G. Gonçalves e Edilaine Alves, e aos estagiários Janaína Dias de Oliveira e José Ernesto Pim. N. da Silva.

\section{REFERÊNCIAS}

ALVARENGA,A.A. Avaliação de cultivares porta-enxertos e produtoras de videira (Vitis spp.) em condições de solos ácidos e alumínio. 2001. 153f. Tese (Doutorado em Agronomia) - Universidade Federal de Lavras, Lavras, 2001.

AMARO, A.A. Mercado de uva de mesa. In: REGINA, M. de A. et al. (Ed.). Viticultura e enologia: atualizando conceitos. Caldas: EPAMIG-FECD, 2002.p.83-106.

BENATO, E.A. Tecnologia, fisiologia e doenças pós-colheita de uvas de mesa. In: POMMER, C.V. (Ed.). Uva: tecnologia de produção, 
pós-colheita, mercado. Porto Alegre: Cinco Continentes, 2003. p.635723.

BOTELHO, R.V. Efeitos do thidiazuron e do ácido giberélico sobre as características dos cachos dos cultivares de videira Vênus, Centennial Seedless e Niagara Rosada. 2002. 136f. Tese (Doutorado em Agronomia) - Faculdade de Ciências Agronômicas, Universidade Estadual Paulista "Júlio de Mesquita Filho", Botucatu, 2002.

BRASIL. Ministério de Agricultura, Pecuária e Abastecimento, Departamento de Fomento e Fiscalização da Produção Vegetal, Divisão de Classificação de Produtos Vegetais. Anexo III: Uva Rústica. Instrução Normativa/SARC n ${ }^{\circ}$ 001, Brasília, DF. 01/02/2002. $27 \mathrm{p}$.

CATO, S.C. Efeito do armazenamento e de doses de ácido giberélico na frutificação das uvas 'Niagara Rosada' e 'Vênus' nas regiões Noroeste e da Alta Paulista do Estado de São Paulo. 2002. 112f. Dissertação (Mestrado) - Escola Superior de Agricultura Luis de Queiroz, Piracicaba, 2002.

GALET, P. Précis de viticulture. $6^{\text {th }}$ ed. Paris: Imprimerie Déhan, 1993. 582p.

GOBBATO, C. Manual do vitinicultor brasileiro. Porto Alegre: Livraria Globo.1940.v.1, 422p.

GUILHARDI, A.A.; MAIA, M.L. Tecnologia, custo de produção e rentabilidade do cultivo de uva Niagara no Estado de São Paulo. Informações Econômicas, São Paulo, v.31, n.12, p.48-64, 2001.

MANERA, R. Plantas que mais dão do que tiram do chão. Globo Rural, Rio de Janeiro, v.1, n.7, p.64-71, 1986.

PEDRO JÚNIOR, M.J.; SENTELHAS, P.C.; POMMER, C.V.; MARTINS, F.P.; GALLO, P.B.; SANTOS, R.R.; BOVI, V.; SABINO, J.C. Caracterização fenológica da videira "Niagara Rosada" em diferentes regiões paulistas. Bragantia, Campinas, v.52, n.2, p.153$160,1993$.

POMMER, C. V.; PIRES, E. J. P.; TERRA, M. M.; PASSOS, I., R. da S.; RIBEIRO, I.A. Uvas (Vitis spp.). In: FAHL, J.I. et al. (Ed.). Instruções agrícolas para as principais culturas econômicas. 6.ed. Campinas: Instituto Agronômico, 1998. p.158-162 (Boletim, 200).
QUEIROZ-VOLTAN, R.B.; PIRES,E.J.P. A Videira. In: POMMER, C.V. (Ed.).Uva: tecnologia de produção, pós-colheita, mercado. Porto Alegre: Cinco Continentes, 2003. p.37-61.

SENTELHAS, P.C.; PEREIRA, A.R. Zonas agroclimáticas de maturação para a produção de uvas de mesa no Estado de São Paulo, Brasil. In: REUNIÓN ARGENTINA Y LATINOAMERICANA DE AGROMETEOROLOGIA, 7/1., 1997, Buenos Aires. Actas... Buenos Aires: Asociación Argentina de Agrometeorología, 1997. Seção 1, p.17-18, 1997.

SOUSA, J.S.I. de (Coord.). Uvas para o Brasil. Piracicaba: FEALQ, 1996, v.1, 791p.

SOUSA, J. S. I. de; TERRA, M.M.; DECHEN, A.R. Adubação e nutrição da videira. In: SOUSA, J. S. I. de. (Coord.). Uvas para o Brasil. Piracicaba: FEALQ, 1996. v.1, p.393-424.

TERRA, M.M.; PIRES, E. J. P.; POMMER, C.V.; PASSOS, I.R.S.; MARTINS, F.P.; RIBEIRO, I.J.A. Comportamento de porta-enxertos para o cultivar de mesa Niagara Rosada em Jundiaí-SP. In: CONGRESSO BRASILEIRO DE FRUTICULTURA, 9., 1987, Campinas. Anais... Campinas: Sociedade Brasileira de Fruticultura, 1988. v.2, p.721-725.

TERRA, M. M.; PIRES, E. J. P.; NOGUEIRA, N. A. M. Tecnologia para produção de uva Itália na região Noroeste do Estado de São Paulo. 2.ed. Campinas: CATI, 1998. 81p. (Documento Técnico, 97).

WUTKE, E. B. Resultados de pesquisas com adubação verde intercalar na videira Niagara. Dia de Campo, Indaiatuba-SP, 31 de maio de 2001. Mimeo.

WUTKE, E.B.; CARVALHO, C.R.L.; COSTA,F.; TERRA, M.M.; PIRES, E.J.P.; SECCO, I.L.; RIBEIRO, I.J.A. Qualidade de frutos de videira 'Niagara Rosada' em cultivo intercalar com gramínea e leguminosas. Revista Brasileira de Fruticultura, Jaboticabal, v.26, n.1, p.92-96, 2004. 